\title{
Comparative study of maximum respiratory pressure in adults from amazonas by different predictive equations
}

\author{
Cássio Daniel Araújo Da Silva'; Fernanda Figueirôa Sanchez'; Maria Clara De Souza Pereira Gama Maciel'; \\ Madria Andrade Figueira'; Elisa Brosina De Leon'; Roberta Lins Gonçalves
}

\begin{abstract}
Introduction: The measurement of muscular strength and maximum static pressures, substantially a consecrated and practical method, raise discussions about reference values and predictive equations, taking into account the heterogeneity of the studies. Objectives: Compare predicted values of IPmax and EPmax with the equations of Neder et al., 1999 and Costa et al., 2010 in adult individuals from the state of Amazonas (AM, Brazil). Method: A cross-sectional study in which was evaluated the Maximum Respiratory Pressures (IPmax and EPmax) according to standardization of the Brazilian Society of Pneumology and Tisiology in 210 individuals ( $68 \%$ female and $32 \%$ male) and 109 were eutrophic and 101 with overweight. The age of the individuals was $47,8 \pm 18,5$ years. For comparative statistical analysis between the values obtained and predicted by the equations was performed the Anova One Way-Software SigmaStat 3.5 test. Results: The comparison of the values obtained with those predicted revealed that the Neder et al underestimated the IPmax in both genders $(P<0,001)$ and overestimated the EPmáx in males $(P<0,001)$. While the equation of Costa et al overestimated the IPmax and EPmáx in males $(P<0,001)$ underestimated the IPmax in females $(P<0,001)$. Conclusion: The results evidenced divergences in the predictive quality of the equations used, especially for IPmax, which suggests the low specificity of it in the population evaluated.
\end{abstract}

Keywords: Respiratory muscles; Reference values; Evaluation.

\section{INTRODUCTION}

Measurement of maximum respiratory pressures (MRP) represents, quantitatively, the strength of the respiratory muscles, called IPmax and EPmax (maximum inspiratory pressure and maximum expiratory pressure, respectively), being a practical and non-invasive method of clinical evaluation, ${ }^{(1-3)}$ with recognized diagnostic and prognostic value. ${ }^{(2,4-6)}$ However, there are many factors that must be taken into account during the execution of these measures, such as the interference of personal (height, weight, physical fitness, individual motivation), methodological (type of device, operator experience, execution of maneuvers) or population (such as the anthropometric characteristics of the population) values. ${ }^{(5,7,8)}$ Thus, the reference equations, which are essential for the diagnosis of muscle weakness, should be able to predict such influences; Otherwise, these equations may underestimate or overestimate the values and compromise the analysis of the results obtained. ${ }^{(2,5,9)}$
In Brazil, specifically, some studies were carried out aiming to establish reference values for the population, including: Camelo Jr et al (1985), were the first to suggest reference values for the Brazilian population; ${ }^{(10)}$ Neder et al (1999), proposed predictive equations for the Brazilian population as well; (11) Parreira et al (2007), concluded that the equations proposed by Neder et al were not able to predict the IPmax and EPmax values in the target population; ${ }^{(12)}$ Costa et al (2010), suggested new equations for the Brazilian population; (4) and Pessoa et al, recently pointed out methodological failures in previous studies. ${ }^{(2)}$ However, some studies have questioned the reliability of some of these equations, raising the importance of investigating heterogeneous factors and its applicability in different populations. ${ }^{(2,9,12)}$ Due to these discrepancies and the lack of reference values in the population of the Amazon region, the objective of the present study was to compare the predicted and obtained IPmax and EPmax 
values by the equations of Neder et al and Costa et al in an adult population.

\section{METHOD}

\section{Design and Sample}

A cross-sectional study approved by the Research Ethics Committee of the Federal University of Amazonas - UFAM (CAAE: 45586815.0.0000.5020). The study included 210 adults recruited by convenience sampling and evaluated at the Faculty of Physical Education and Physiotherapy of Federal University of Amazonas.

\section{Inclusion and exclusion criteria}

Subjects were included in the study as they presented the eligibility criteria, namely: presenting a clinical situation with no history of recent comorbidities and adequate physical-cognitive ability to perform the test. Exclusion criteria included smokers, those with a history of respiratory or cardiovascular disease, as well as individuals with any neuromuscular disease that prevented them of performing the tests. The BMI was calculated through of the following formula: $\mathrm{BMI}=$ weight $(\mathrm{kg}) /$ height $^{2}\left(\mathrm{~m}^{2}\right)$, and categorized considering the intervals of $18.6-24.9 \mathrm{~kg} / \mathrm{m}^{2}$ for eutrophy and 25.0-29.9 $\mathrm{kg} / \mathrm{m}^{2}$ for overweight.

\section{Determination of maximum respiratory pressures}

The respiratory muscle strength test was performed following the Guidelines for Pulmonary Function Tests recommended by the Brazilian Society of Pulmonology and Tisiology. ${ }^{(13)}$ Measurements of MRP were performed using an analogue manovacuometer of Wika ${ }^{\circledR}$ brand, calibrated and phased in $\pm 300 \mathrm{cmH}_{2} \mathrm{O}$. The subjects were instructed to remain seated with their feet supported and to use nasal clip, avoiding air leakage. The IPmax was measured from the residual volume, and the PEmax pressure from the lung total capacity. The position reached at the end of the maximum efforts was maintained for at least one second to characterize the plateau pressure, and it was observed if at least two maneuvers had their values different from each other and not higher than $10 \%$ of the highest value. At the end of the four maneuvers with intervals of 1 minute were considered as the IPmax and EPmax the highest value obtained.

\section{Statistical analysis}

The data were processed and analyzed in Software SigmaStat 3.5 for calculation of simple means, standard deviation of the mean and ANOVA One Way Test for comparison between the values obtained and predicted by the equations, setting $\mathrm{P}<0.05$ as value of statistical significance.

\section{RESULTS}

The study included two hundred and ten $(N=210)$ individuals, of which 109 were eutrophic and 101 overweight; $68 \%$ of the individuals were female and $32 \%$ male. The characteristics of the study population are described in Table 1.

The distribution of MRP among the age groups is shown in Table 2. A certain trend towards a linear decline of IPmax and EPmax in age-related is observed, with IPmax from the 40-49 age group and EPmax in the range of 50-59.

The comparison between the measured and predicted values of IPmax and EPmax by equations of Neder et al and Costa et al are shown in the Tables 3 and 4, respectively. In addition to the discrepancies between the values obtained in the studied population and those predicted, stand out the inter-equation differences, evidenced in the male IPmax $(-116.1 \pm 16.3$ to Neder et al and $-171.6 \pm 25.5$ to Costa et

Table 1. Description of the study population.

\begin{tabular}{|c|c|c|c|}
\hline \multicolumn{2}{|c|}{ VARIABLES } & \multirow{2}{*}{$\frac{N}{143}$} & \multirow{2}{*}{$\begin{array}{c}\% \\
68.0\end{array}$} \\
\hline Gander & Female & & \\
\hline & Male & 67 & 32.0 \\
\hline \multirow{7}{*}{ Age Group (years) } & $18-29$ & 48 & 23.0 \\
\hline & $30-39$ & 21 & 10.0 \\
\hline & $40-49$ & 39 & 18.5 \\
\hline & $50-59$ & 41 & 19.5 \\
\hline & $60-69$ & 37 & 18.0 \\
\hline & $70-89$ & 24 & 11.0 \\
\hline & & MEAN & SD \\
\hline Age (years) & & 47.5 & 17.9 \\
\hline Height (m) & & 1.60 & 0.09 \\
\hline Weight (Kg) & & 64.4 & 10.0 \\
\hline BMI $\left(\mathrm{kg} / \mathrm{m}^{2}\right)$ & & 25.0 & 2.7 \\
\hline $\operatorname{IPmax}\left(\mathrm{cm} / \mathrm{H}_{2} \mathrm{O}\right)$ & & -113.5 & 57.6 \\
\hline $\operatorname{EPmax}\left(\mathrm{cm} / \mathrm{H}_{2} \mathrm{O}\right)$ & & 95.2 & 34.9 \\
\hline
\end{tabular}

IPmax- Maximum inspiratory pressure; EPmax- Maximum expiratory pressure; S.D.- Standard deviation; BMI- Body Mass Index.

Table 2. Distribution of IPmax and EPmax stratified by age group.

\begin{tabular}{cccccc}
\hline & \multicolumn{2}{c}{ IPmax } & & \multicolumn{2}{c}{ EPmax } \\
\cline { 2 - 3 } \cline { 5 - 6 } Age Group & Mean & S.D. & & Mean & S.D. \\
\cline { 2 - 3 } $18-29$ & -113.6 & 55.3 & & 101.6 & 38.0 \\
$30-39$ & -148.3 & 73.2 & & 100.7 & 38.3 \\
$40-49$ & -125.6 & 63.1 & & 102.3 & 35.6 \\
$50-59$ & -114.4 & 54.3 & & 98.5 & 30.4 \\
$60-69$ & -100.5 & 50.7 & & 87.0 & 29.5 \\
$70-89$ & -81.5 & 28.3 & 72.9 & 30.4 \\
\hline
\end{tabular}

IPmax- Maximum inspiratory pressure; EPmax- Maximum expiratory pressure; S.D.Standard Deviation. 
Table 3. Comparison between the inspiratory muscle strength evaluated and predicted by the equations of Neder et al (1999) and Costa et al (2010):

\begin{tabular}{|c|c|c|c|c|}
\hline & $\begin{array}{l}\text { Obtained } \\
\text { values }\end{array}$ & Neder et al & Costa et al & Valor de $\mathbf{P}$ \\
\hline & IPmax & IPmax & IPmax & \\
\hline Males & $-122.8 \pm 63.1 \#$ & $-116.1 \pm 16.3 \# *$ & $-171.6 \pm 25.5 \# *$ & $P=<0.001$ \\
\hline Females & $-109.2 \pm 54.6 \#$ & $-87.5 \pm 31.2 \# *$ & $-53.0 \pm 7.7 \# *$ & $P=<0.001$ \\
\hline
\end{tabular}

Maximum inspiratory pressure; \#statistically significant difference between obtained and predicted values in the Anova One Way Test; *statistical difference between the equations of Neder et al. and Costa et al.,; significance value set in $p<0.05$.

Table 4. Comparison between the expiratory muscular strength evaluated and predicted by the equations of Neder et al (1999) and Costa et al (2010):

\begin{tabular}{ccccccc}
\hline & $\begin{array}{c}\text { Obtained } \\
\text { values }\end{array}$ & & Neder et al & & Costa et al & Valor de P \\
\cline { 2 - 3 } & EPmax & EPmax & EPmax & \\
\cline { 1 - 2 } Males & $111.6 \pm 36.9 \#$ & $-125.6 \pm 16.5 \#$ & $121.6 \pm 25.6 \#$ & $\mathrm{P}=<0.001$ \\
Females & $87.5 \pm 31.2$ & $87.1 \pm 8.2$ & $87.6 \pm 11.4$ & $\mathrm{P}=0.925$ \\
\hline
\end{tabular}

EPmax- Maximum expiratory pressure; \# statistically significant difference between obtained and predicted values in the Anova One Way Test; significance value set in $p<0.05$.

al) $(\mathrm{P}<0.001)$ and female IPmax $(-87.5 \pm 31.2$ to Neder et al and $-53.0 \pm 7.7$ to Costa et al) $(P<0.001)$. In the females, no differences were observed between the formulas regarding the EPmax.

\section{DISCUSSION}

The present study had as objective to compare the values obtained and predicted for the MRP between the Brazilian equations of Neder et al (1999) and Costa et al (2010) in a population composed of adult individuals from the state of Amazonas (AM, Brazil). We observed, in general, that the equations were not able to predict the values obtained, in particular of the IPmax.

Considering the numerous studies on the subject, Pessoa et al. (2014), in a systematic review, gathered 22 researches, which represented populations of North America, Brazil, Sweden and Netherlands. Among the findings, it is worth mentioning the great inter-study variation of the normative values of IPmax, according to the authors, can be attributed to the following factors: methodological aspects (such as the understanding of the maneuver and the adequate technical execution) and especially the characteristics of the participants, since reference values are a reflection of women and men of different ethnicities, with particularities expressed in body height and that may represent variations between evaluated and predicted values. As for the prediction variables of the equations, in general, it was observed that, while gender and age are the most reliable and used, others, such as height, have been presented as a positive predictor, negative or non-predictive of respiratory pressures. ${ }^{(9)}$

The equations of Neder et al (1999) ${ }^{(11)}$ and Costa et al (2010) ${ }^{(4)}$, both based on populations of the urban region of southeastern of the Brazil, determined in their formulas the variables age and gender as independent predictors of respiratory pressures. Between the two studies, it is possible to identify similar findings regarding the negative effect of age on respiratory muscle strength. Thus, in our results we found that there is a tendency of drop in the values of the maximum inspiratory pressure from the age group between $40-49$ years in the two groups and the expiratory pressure presented a linear reduction from the age range of 50-59 years, also in the two groups. While some studies reinforce this trend, $(1,14,15)$ Pessoa et al (2014) verified, in an intriguing way, a surprising increase in the values evaluated in individuals with $50-59$ years, justifying the finding because there was an expressive number of active and motivated individuals in this age group in the study. ${ }^{(2)}$ About this discussion, Bessa et al (2015) suggest that decreased mobility with aging may be caused by reduced muscle strength and potency and mediated by reduction in spirometric parameters. ${ }^{(3)}$ In addition, this decrease in skeletal muscle strength was associated with a reduction in lung function, and this association between pulmonary function and mobility in healthy older adults is still uncertain, ${ }^{(16)}$ and it is also uncertain the point of decline respiratory pressures by age. ${ }^{(9)}$

The comparison between the values obtained and predicted revealed interesting results: While the equation of Neder et al underestimated the IPmax in both genders and overestimated the EPmax in males, the equation of Costa et al overestimated IPmax and EPmax in males and underestimated IPmax in females. However, the EPmax values for both equations were shown to be equivalent for females, with no significant differences.

Earlier studies proceeded with this comparison between equations: Leal et al (2007), compared values obtained from 495 healthy sedentary adults with three equations, including the Neder et al, checking, in general, that most of the predicted values overestimated those found, and that EPmax predicted by the equation showed no difference with the assessed values in female. In our findings, we also found that the Neder formula overestimated the EPmax values for males; however, it underestimated the IPmax values in this population. ${ }^{(17)}$ Parreira et al (2007), on the other hand, evaluated 100 healthy individuals (54 females, 46 males) also from the southeast region and comparing with the values of Neder et al, verified the following results: In females, the measured IPmax was significantly lower than the predicted values $(p=0.000)$, whereas EPmax did not present these discrepancies; in males, the IPmax evaluated did not present significant differences with the predicted one, whereas the EPmax was underestimated by the equation $(p=0.017)$. In general, it was concluded in the study that the equation of Neder et al was not able to predict the values in a reliably way; ${ }^{(12)}$ While in our study, although EPmax did not show differences with Neder et al values, IPmax in females was significantly underestimated. These differences can be explained, according to Leal et al (2007), because the 
equation of Neder et al used few anthropometric variables as predictors of MRP.

Finally, the study of Forti et al (2012) compared the predicted values by Costa et al and Neder et al, but this time in a population of morbidly obese females $(N=30)$ and a control group consisting of eutrophic $(\mathrm{N}=30)$. Among the results, there were also significant discrepancies between the values obtained and predicted in the eutrophic and obese population: IPmax overestimated by the formula of Neder et al and underestimated by Costa et al; also highlights the difference in the values predicted by the two equations, which reinforces our findings. ${ }^{(18)}$

We believe that the differences between the values obtained and those predicted by the equations in the present study are mainly a reflection of the characteristics of the studied sample. Thus, it should be emphasized that the population of Amazonas has a very heterogeneous origin, being composed by white $(24.2 \%)$, black $(3.1 \%)$, mulattos or mestizos (66.9\%), indigenous (4.0\%) and mogolian (0.3\%), ${ }^{(19)}$ which gives this population anthropometric characteristics of its own, such as short stature, for example. In our study population, mean height was $1.60 \pm 0.9 \mathrm{~m}$ (meters), while the national average is in the range of $1.73 \mathrm{~m} .{ }^{(20,21)}$. As Parreira et al (2007), we emphasize the importance of future studies to determine parameters of maximum respiratory pressures that aim to establish adequate reference values for the populations of the different regions of Brazil. ${ }^{(12)}$ We can point out as limitations of the present study, the non-evaluation of pulmonary function by spirometry and the lack of a digital instrument for the evaluation of respiratory muscle strength.

\section{CONCLUSION}

The results of this study indicate differences in the predictive quality of both equations for maximal respiratory pressures, especially the inspiratory. In addition, a large inter-equation variation was detected, which attenuates the need for equations capable of predicting, in a more reliable way, the values of respiratory pressures in the different Brazilian regions.

\section{AUTHORS' CONTRIBUTIONS}

CDAS, MCSPGM, MAF, FFS - Data collection and search of articles; CDAS, FFS, RLG - Elaboration of the article; FFS, RLG, EBL - Guidance and supervision.

\section{CONFLICT OF INTEREST}

The authors declare that they have no conflicts of interest.

\section{REFERENCES}

1. Black LF, Hyatt RE. Maximal respiratory pressures: normal values and relationship to age and sex. Am Rev Respir Dis.1969;99(5):696-702.
2. Pessoa IMBS, Neto MH, Montemezzo D, Silva LAM, Andrade AD, Parreira VF. Predictive equations for respiratory muscle strength according to international and Brazilian guidelines. Braz J Phys Ther. Braz J Phys Ther. 2014;18:410-418.

3. Bessa EJC, Lopes AJ, Rufino R. A importância da medida da força muscular respiratória na prática da pneumologia. Pulmão RJ 2015;24(1):37-41.

4. Costa D, Gonçalves HA, Lima LP, Ike D, Cancelliero KM, Montebelo MI. New reference values for maximal respiratory pressures in the Brazilian population. J Bras Pneumol. 2010;36(3):306-12.

5. Harik-Khan RI, Wise RA, Fozard JL; The Baltimore Longitudinal Study of Aging. Determinants of maximal inspiratory pressure. Am J Respir Crit Care Med. 1998;158(5 Pt 1):1459-64.

6. Karvonen, J., S. Soarelainen, and M. M. Nieminen. 1994. Measurement of respiratory muscle forces based on maximal inspiratory and expiratory pressures. Respiration 61:28-31.

7. Enright, P. L., R. A. Kronmal, T. A. Manolio, M. B. Schenker, and R. E. Hyatt. 1994. Respiratory muscle strength in the elderly. Am. J. Respir. Crit. Care Med. 149:430-438

8. Enright PL, Adams AB, Boyle PJ, Sherrill DL. Spirometry and maximal respiratory pressure references from healthy Minnesota 65- to 85-yearold women and men. Chest. 1995;108(3):663-9.

9. Pessoa IMBS, Franco Parreira V, Fregonezi GAF, Sheel AW, Chung F, Reid WD. Reference values for maximal inspiratory pressure: a systematic review. Can Respir J. 2014;21(1):43-50.

10. Camelo Jr JS, Terra Filho J, Manço JC. Pressões respiratórias máximas em adultos normais. J Pneumol. 1985;11(4):181-4.

11. Neder JA, Andreoni S, Lerario MC, Nery LE. Reference values for lung function tests. II. Maximal respiratory pressures and voluntary ventilation. Braz J Med Biol Res.1999;32(6):719-27.

12. Parreira VF, França DC, Zampa CC, Fonseca MM, Tomich GM, Britto RR. Pressões respiratórias máximas: valores encontrados e preditos em indivíduos saudáveis. Rev Bras Fisioter. 2007;11(5):361-8.

13. Sociedade Brasileira de Pneumologia e Tisiologia. Diretrizes para Testes de Função Pulmonar 2002. J Bras Pneumol 2002;28(Supl 3):155-65.

14. Simões RP, Deus AP, Auad MA, Dionísio J, Mazzonetto M, Borghi-Silva A. Maximal respiratory pressure in healthy 20 to 89 year-old sedentary individuals of central São Paulo State. Rev Bras Fisioter. 2010;14(1):60-7.

15. Hautmann $\mathrm{H}$, Hefele $\mathrm{S}$, Schotten $\mathrm{K}$, Huber RM. Maximal inspiratory mouth pressures (MIP) in healthy subjects - what is the lower limit of normal? Respir Med. 2000;94(7):689-93.

16. Sllanpaa E, Stenroth L, Bijlma AY, Rantanen T, McPhee JS, Maden-Wilkinson TM et al. Association between muscle strength, spirometric pulmonary function and mobility in healthy older adults. Age 2014;36(4):9667.

17. Leal AH, Hamasaki TA, Jamami M, Di Lorenzo VAP, Pessoa BV. Comparação entre valores de força muscular respiratória medidos e previstos por diferentes equações. Fisioter Pesqui. 2007;14(3):25-3.

18. Forti EMP, Souza FSP, Mendes CP, Junior IR, Moulim MB. Comportamento da força muscular respiratória por diferentes equações preditivas. Rev Bras Fisioterapia. 2012;16(6):479-86.

19. Cerqueira FW. Aspectos da população do Amazonas. Brasil Escola. Disponível em <http://brasilescola.uol.com.br/brasil/aspectospopulacao-amazonas.htm>. Acesso em 12 de novembro de 2016.

20. Disponível em <http://g1.globo.com/ciencia-e-saude/noticia/2016/07/ brasileiro-cresce-em-altura-nos-ultimos-cem-anos-mas-ainda-e-baixinhoconheca-o-ranking-global.html>, acesso em 12 de novembro de 2016.

21. Disponível em <http://www.amazonas.am.gov.br/o-amazonas/dados/>, acesso em 12 de novembro de 2016. 